\title{
0699 PRE-HOSPITAL MANAGEMENT IN TERRORIST MCI'S IN PUNJAB, PAKISTAN-YEAR 2009
}

H Waseem, J A Razzak, R Naseer, A Mehmood* Correspondence: Punjab Emergency Services, IH-70, Falcon Complex Gulberg -3 Lahore 75500, Pakistan

10.1136/ip.2010.029215.699

Background Pakistan has seen a huge surge in terrorist attacks in the last two years which has led to extensive loss of life and property. Major disaster events have resulted due to terrorism and at such times rescue missions and evacuation becomes a challenge especially in a developing country.

Objective The purpose was to formally evaluate and document the role that the government based EMS known as Rescue 1122 is playing in terrorist attacks.

Methods Data was collected retrospectively from the EMS sources. Twenty incidents had occurred in Punjab in the year 2009 and all of these were included. The response time, number of vehicles and personnel used, the number of total casualties evacuated and where they were evacuated were studied. Interagency liaison was also studied.

Limitations Missing data was found in one city regarding resources and patients transported. It is presented as such.

Results It was noted that 19 out of 20 were in urban areas and consequently had short response time. Almost 50\% were large MCl's. The average time of first responders was $5 \mathrm{~min}$ and the time of complete evacuation was $4 \mathrm{~h}$. Other agencies involved most often were Military, Police and then Fire services. A volunteer ambulance service was also identified. The casualties were evacuated to predesignated hospitals but evacuation seems to be dependant more on geographical proximity then the capacity of hospitals. This will be further discussed in recommendations. 